\title{
Pengaruh Persentase Serat Sabut Kelapa dan Foam Agent Terhadap Sifat Fisik dan Mekanik Papan Beton
}

\author{
Riefli Fatmi*, Alimin Mahyudin \\ Jurusan Fisika FMIPA Universitas Andalas \\ Kampus Unand Limau Manis Padang 25163 \\ *rieflifatmi16@gmail.com
}

\begin{abstract}
ABSTRAK
Telah dilakukan penelitian mengenai pengaruh persentase serat sabut kelapa dan foam agent terhadap sifat fisik dan mekanik papan beton. Variasi persentase serat $0 \%, 0,3 \%, 0,6 \%, 0,9 \%$ dan $1,2 \%$ menggunakan metode penyusunan serat secara acak. Sifat fisik dan mekanik yang diujikan meliputi densitas, daya serap air, porositas, kuat tekan dan kuat lentur. Penambahan serat sabut kelapa dan foam agent dapat membuat papan beton menjadi lebih ringan dibandingkan dengan papan GRC yang beredar di pasaran. Dari hasil pengujian didapatkan nilai densitas yang terendah diperoleh pada persentase serat sabut kelapa 0,9\%. Penambahan 0,9\% serat sabut kelapa dan 0,6\% foam agent merupakan persentase optimum dalam pembuatan papan beton. Nilai densitas papan beton sudah memenuhi standar SNI 032105-2006 dan nilai kuat tekan serta kuat lentur sudah memenuhi standar SNI 03-3449-2002.

Kata kunci: foam agent, kuat lentur, kuat tekan, serat sabut kelapa
\end{abstract}

\section{ABSTRACT}

The research on the effect of percentage of coco fiber and foam agent to the physical and mechanical properties of concrete board has been conducted. Variations in the percentage of fiber were 0\%, 0.3\%, $0.6 \%, 0.9 \%$ and $1.2 \%$ using randomly fiber arrangement. Physical and mechanical properties that was tested include density, water absorption, porosity, compressive strength and flexural strength. Addition of coco fiber and foam agent make concrete boards lighter than commercial GRC board. The results show that, the lowest density values obtained in the percentage of $0.9 \%$ coco fiber. The addition of $0.9 \%$ coco fiber and $0.6 \%$ foam agent is an optimum percentage for the concrete board. The density of concrete board already met SNI standard 03-2105-2006 and the compressive strength and flexural strength to meet the SNI standard 03-3449-2002.

Keywords: foam agent,flexural strength, compressive strength.

\section{PENDAHULUAN}

Inovasi menjadi bagian penting dalam sebuah konstruksi bangunan salah satunya sebagai partisi dinding seperti papan beton. Papan beton adalah salah satu produk komposit yang terbuat dari campuran partikel atau bahan berlignoselulosa lainnya dengan semen sebagai perekatnya (Sutigno,1977). Berdasarkan perkembangan saat ini papan beton dibuat sederhana atau dibuat semakin tipis dengan ketebalan kecil dari $10 \mathrm{~mm}$. Semakin tipis ketebalan beton semakin halus agregat yang digunakan. Papan beton banyak digunakan yaitu GRC board (Glass-Fiber Reinforced Cement). GRC board adalah papan semen fiber-glass yang ringan, tahan kelembaban dan tidak mudah lapuk (Putranto, 2017).

Berbagai penelitian tentang papan beton ringan telah banyak dilakukan sebagai upaya penyempurnaan fungsi pemakaian dan kekuatan beton ringan, seperti pemakaian bahan komposit dalam pembuatannya. Kebutuhan untuk menghasilkan material komposit baru sebagai pengganti bahan papan terus dilakukan. Material komposit tersebut harus memiliki dampak positif bagi lingkungan hidup serta sebagai alternatif dari material konvensional yang telah lama digunakan. Material komposit merupakan campuran dari dua atau lebih bahan. Pada umumnya material komposit terdiri dari dua ikatan yang dikenal dengan matrik dan serat alam (Hull, 1981).

Beberapa peneliti telah membuat komposit serat sabut kelapa dalam pembuatan papan beton. Zulkifly (2013) telah melakukan penelitian tentang pengaruh penambahan serat sabut kelapa terhadap kuat tekan pada beton normal mendapatkan hasil bahwa dengan adanya penambahan serat sabut kelapa pada beton dapat meningkatkan kuat tekan beton yakni diperoleh kuat tekan optimum sebesar 20,38 Mpa pada proporsi penambahan serat 0,3\% dimana melebihi kuat tekan beton normal yakni 19,96 MPa. 
Pembuatan papan beton juga dilakukan dengan membuat gelembung- gelembung udara dalam adukan semen dan agregat halus. Gelembung-gelembung pada bahan campuran beton tersebut merupakan bahan tambahan (additive) yang berbentuk foam (busa). Dengan adanya teknologi foam, volume semen dan agregat halus dari papan beton berkurang sehingga papan peton tersebut jadi ringan (Umar, 2014).

Murtono (2015) telah melakukan penelitian tentang pemanfaatan foam agent dan material lokal dalam pembuatan beton ringan. Hasil penelitian didapatkan bahwa penambahan foam agent sebesar 0,6\% dari volume memiliki kuat lentur 0,738 MPa dan kuat tekan 4,02 MPa paling tinggi dibandingkan variasi lainnya seperti $0,8 \%$ atau $1 \%$ dari volume papan beton tersebut.

Berdasarkan penelitian yang telah dilakukan sebelumnya, maka dilakukan penelitian yang bersifat eksperimental mengenai "pengaruh persentase serat sabut kelapa dan foam agent terhadap sifat fisik dan mekanik papan beton". Penambahan serat kelapa dan foam agent terhadap beton pada penelitian ini diharapkan dapat membuat dan membandingkan papan beton ringan dengan standar mutu papan serta mengetahui persentase optimum dan pengaruh penambahan serat sabut kelapa pada papan beton.

\section{METODE}

Bahan yang digunakan dalam penelitian ini adalah serat sabut kelapa yang berguna sebagai penguat ikatan matrik yang panjangnya $3 \mathrm{~cm}$ dengan variasi serta $0 \%, 0,3 \%, 0,6 \%$, $0,9 \%$ dan $1,2 \%$. Sedangkan bahan matriks yang digunakan adalah semen,pasir,air, foam agent dan air. Papan beton ringan yang dibuat berukuran $5 \times 5 \times 1 \mathrm{~cm}^{3}$ untuk pengujian densitas, daya serap air,porositas dan kuat tekan.Sedangkan untuk pengujian kuat lentur dibuat dengan ukuran $20 \times 5 \times 1 \mathrm{~cm}^{3}$.

Proses selanjutnya dilanjutkan dengan pembuatan papan beton ringan dengan menggunakan metode komposit serat yaitu pembentukan lapisan laminat dengan tiga lapis, lapisan atas dan bawah untuk campuran pasta beton dengan foam agent dan lapisan tengah untuk serat sabut kelapa. Sebelum membuat adanan pasta beton campur foam agent. Semua bahan ditimbang terlebih dahulu dengan perbandingan bahan yang telah ditentukan menggunakan timbangan digital.

Pembuatan adonan dilakukan dengan cara dicampur dan diaduk secara merata, setelah merata adonan dimasukkan kedalam cetakan yang telah disiapkan. Papan beton yang telah dicetak dikeringkan selama 28 hari pada suhu ruang sebelum digunakan untuk pengujian (Wuryati,2001).

\subsection{Pengujian Densitas}

Papan beton ringan yang bermassa kering (gr) ditimbang dengan menggunakan timbangan digital, kemudian diukur besar volume pada papan beton. Maka nilai densitas papan beton ringan dapat diketahui dengan cara membagi massa per volume yang berdasarkan Persamaan 2.

$$
\rho=\frac{m}{V}
$$

dengan $m$ adalah massa sampel uji kondisi kering (gr) dan $V$ adalah volume sampel $\left(\mathrm{cm}^{3}\right)$.

\subsection{Pengujian Daya Serap Air}

Pengujian daya serap air dilakukan pada sampel uji densitas. Mula-mula sampel uji dilakukan perendaman dalam wadah berisi air pada suhu $25^{\circ} \mathrm{C}$ selama 24 jam. Lalu sampel uji diangkat dan dikeringkan dengan kain agar airnya tidak menetes lagi. Kemudian sampel ditimbang menggunakan neraca digital dan dicatat hasilnya sebagai $\mathrm{m}_{b}$. Setelah itu dilakukan perhitungan menggunakan Persamaan 1 untuk mendapatkan nilai daya serap air.

$$
\text { Daya Serap Air }(\%)=\frac{m b-m k}{m b} \times 100 \%
$$


dengan $m_{k}$ adalah massa sampel uji kondisi kering (gr) dan $m_{b}$ adalah massa sampel uji kondisi basah setelah direndam air (gr).

\subsection{Pengujian Porositas}

Pengujian porositas dilakukan pada sampel uji daya serap air sehingga pengujian porositas dapat langsung bersamaan dengan uji daya serap air. Perhitungan porositas sampel uji menggunakan Persamaan 3.

$$
\text { Porositas }(\%)=\frac{m_{b}-m}{V} \times \frac{1}{\rho_{a}} \times 100 \%
$$

dengan $m$ adalah massa sampel uji kondisi kering (gr), $m_{b}$ adalah massa sampel uji kondisi basah setelah direndam air (gr), $V$ adalah volume sampel uji $\left(\mathrm{cm}^{3}\right)$ dan $\rho_{\mathrm{o}}$ adalah massa jenis dari air $\left(\mathrm{gr} / \mathrm{cm}^{3}\right)$.

\subsection{Pengujian Kuat Lentur}

Mula-mula sampel uji disiapkan dan diukur dimensi lebar dan tebal sampel uji menggunakan jangka sorong dan dicatat hasil pengukuran. Kemudian dilakukan pengujian kuat lentur menggunakan mesin UTM dengan meletakkan sampel uji secara mendatar pada tumpuan. Kemudian dicatat perubahan sampel uji akibat diberi beban secara vertikal (tegak lurus) hingga sampel uji patah sebagai nilai $P$. Setelah itu dilakukan perhitungan nilai kuat lentur menggunakan Persamaan 4.

$$
f_{r}=\frac{3 P L}{2 b d^{2}}
$$

dengan $f_{r}$ adalah kuat lentur $\left(\mathrm{kg} / \mathrm{cm}^{2}\right), P$ adalah beban patah maksimum $(\mathrm{kg}), L$ adalah jarak tumpuan $(\mathrm{cm}), b$ adalah lebar sampel uji $(\mathrm{cm})$ dan $d$ adalah tebal sampel uji $(\mathrm{cm})$.

\subsection{Pengujian Kuat Tekan}

Pengujian kuat tekan dilakukan dengan menggunakan UTM (Universal Testing Machine) uji kuat tekan untuk mengetahui kuat tekan hancur sampel uji. Pengujian dilakukan dengan cara meletakkan sampel uji yang ukuran $5 \times 5 \times 1 \mathrm{~cm}^{3}$ pada bagian mesin tempat meletakkan sampel uji. Kemudian diberikan pembebanan diatas sampel uji tersebut. Skala yang tertera pada mesin uji saat benda uji mengalami retakkan dicatat sebagai hasil beban maksimum (P). Selanjutnya nilai kuat tekan (fc) dapat dihitung dengan menggunakan Persamaan 5.

$$
f_{c}=\frac{P}{A}
$$

dengan $f_{c}$ adalah kuat tekan $\left(\mathrm{kg} / \mathrm{cm}^{2}\right), P$ adalah beban maksimum sampel uji $(\mathrm{kg})$, dan $A$ luas permukaan sampel uji $\left(\mathrm{cm}^{2}\right)$.

\section{HASIL DAN DISKUSI}

\subsection{Densitas}

Hasil pengukuran dan perhitungan menunjukkan nilai densitas tanpa serat atau serat sabut kelapa persentase $0 \%$ memiliki nilai densitas yang cukup tinggi $1,60 \mathrm{gr} / \mathrm{cm}^{3}$, namun seiring dengan penambahan serat sabut kelapa di dalam papan beton menghasilkan nilai densitas semakin menurun. Nilai densitas yang rendah disebabkan oleh adanya rongga udara pada lapisan matrik. Jumlah rongga udara yang terdapat pada papan sebandingan dengan masaa serat sabut kelapa yang digunakan. 


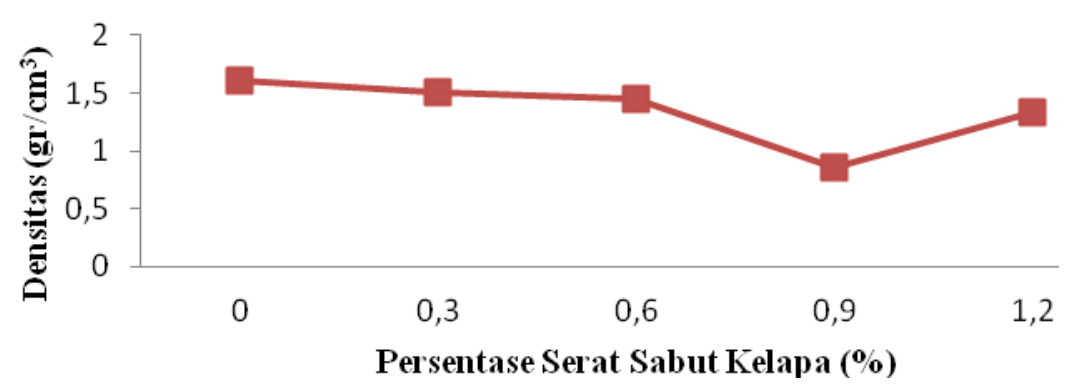

Gambar 1. Pengaruh Persentase Serat Sabut Kelapa dan Foam Agent Terhadap Densitas Papan Beton

Nilai densitas ini masih lebih rendah dibandingkan dengan nilai densitas papan GRC. Hal ini terjadi karena jumlah massa serat yang digunakan cukup banyak sesuai dengan tingginya nilai persentase. Walaupun serat bersifat mengembang tetapi serat tersebut dimampatkan karena papan beton yang dibuat memiliki ketebalan $1 \mathrm{~cm}$ sesuai dengan ukuran cetakan. Pemampatan serat membuat rongga-rongga udara pada papan pun menjadi sedikit. Banyaknya rongga-rongga udara yang ada mengakibatkan nilai densitas pada persentase tinggi menjadi cukup besar.

Pada penelitian ini nilai densitas yang diinginkan adalah nilai densitas terendah karena papan yang diharapkan adalah papan yang ringan namun kuat. Untuk densitas terendah pada penelitian ini didapatkan pada persentase serat $0,9 \%$ dengan nilai $0,85 \mathrm{gr} / \mathrm{cm}^{3}$. Nilai densitas yang rendah dipengaruhi adanya rongga udara pada lapisan matriks, serta bentuk fisik dari serat sabut kelapa yang memiliki diameter yang besar dan melengkung sehingga nilai densitas papan beton ringan berserat sabut kelapa bernilai rendah.

\subsection{Daya Serap Air}

Hasil pengukuran dan perhitungan menunjukkan nilai daya serap air tanpa serat atau serat sabut kelapa persentase $0 \%$ memiliki nilai daya serap air yang cukup rendah yaitu 13,57 $\mathrm{gr} / \mathrm{cm}^{3}$, namun nilai daya serap air tertinggi ditunjukkan oleh persentase serat $1,2 \%$ yakninya $18,43 \mathrm{gr} / \mathrm{cm}^{3}$. Hal ini disebabkan pada persentase ini papan beton yang dicetak tidak memiliki kandungan serat sehingga tidak terdapat rongga-rongga udara kecil. Pada persentase serat $1,2 \%$ terdapat banyak rongga-rongga udara kecil didalam papan terbukti ketika direndam papan terdapat gelembung udara yang cukup banyak.

Daya serap air pada papan dengan persentase $1,2 \%$ pada saat pembuatan papan berpersentase tinggi ini serat dipadatkan agar didapatkan ketebalan papan yang konstan yakninya sebesar $1 \mathrm{~cm}$. Semakin tinggi daya serap air papan beton maka semakin rendah densitasnya.

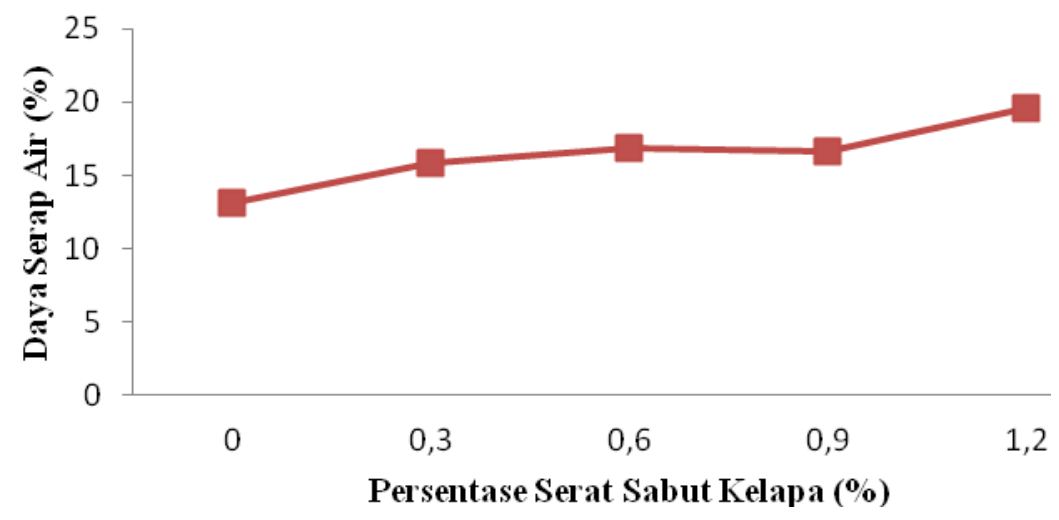

Gambar 2. Pengaruh Persentase Serat Sabut Kelapa dan Foam Agent Terhadap Daya Serap Air Papan Beton 
Keadaan ini terjadi karena pada saat densitas rendah ikatan antar partikel semakin renggang dan terdapat cukup banyak rongga udara dalam lembaran papan. Keadaan ini menyebabkan air atau uap air menjadi mudah mengisi dan terperangkap didalam rongga tersebut yang akan mengakibatkan nilai daya serap air menjadi tinggi, dengan demikian setiap variasi persentase serat ada yang telah memenuhi standar SNI 03-2105-2006 yakni $\leq 14 \%$.

\subsection{Porositas}

Hasil pengujian dan perhitungan menunjukkan bahwa penambahan serat sabut kelapa mempengaruhi porositas papan beton, dimana penambahan serat sabut kelapa menyebabkan porositas meningkat. Kenaikan nilai porositas tertinggi terjadi pada penambahan serat sabut kelapa sebanyak $1,2 \%$. Hal ini menunjukkan bahwa papan beton yang dihasilkan mempunyai pori-pori yang kecil. Ini berarti penambahan persentase serat sabut kelapa terhadap papan beton begitu besar pengaruhnya sehingga semakin besar persentase serat sabut kelapa yang digunakan maka nilai porositas papan yang dihasilkan juga semakin besar.

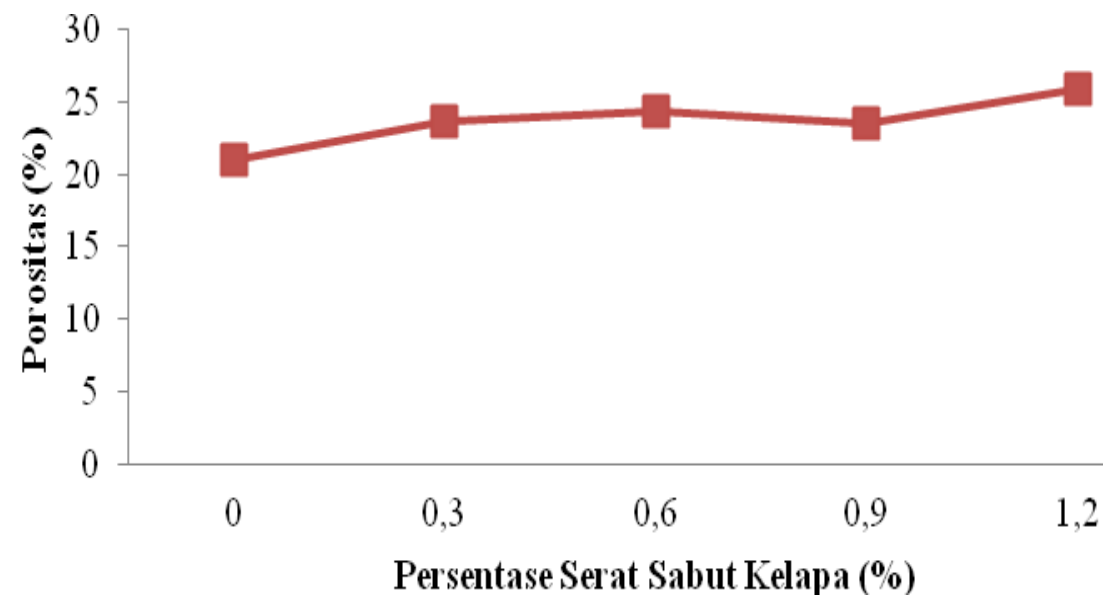

\section{Gambar 3. Pengaruh Pengaruh Persentase Serat Sabut Kelapa dan Foam Agent Terhadap Porositas Papan Beton}

Penambahan serat sabut kelapa dalam papan beton menambah besarnya pori-pori yang terdapat dalam papan beton sehingga papan mudah menyerap air dan menghasilkan nilai porositas yang semakin tinggi. Hubungan porositas dan daya serap air adalah berbanding lurus. Semakin besar nilai daya serap air maka rongga udara pada papan beton juga semakin besar. Hal ini menyebabkan nilai porositas juga semakin besar.

\subsection{Kuat Lentur}

Hasil pengujian dan perhitungan kuat lentur menunjukkan bahwa penambahan serat sabut kelapa mempengaruhi kuat lentur papan beton, dimana penambahan serat sabut kelapa menyebabkan kuat lentur meningkat. Berdasarkan Gambar 4 kuat lentur terendah terdapat pada persentase $0 \%$, ini disebabkan karena papan tidak diperkuat oleh ikatan serat sehingga rekatan antara lapisan matrik menjadi lemah. Pada persentase $0,9 \%$ serat sabut kelapa diperoleh nilai optimum kuat lentur papan komposit beton ringan. Serat sabut kelapa mampu menahan deformasi yang terjadi ketika diberikan pembebanan kepada matrik. Hal ini dikarenakan penambahan massa serat menyebabkan ikatan antar matrik beton yang dihasilkan semakin kuat. Namun penambahan serat sabut kelapa yang berlebihan akan membuat nilai kuat lentur papan komposit beton ringan menurun. Hal ini disebabkan oleh massa beton berkurang, selain itu sifat serat sabut kelapa yang mengembang membuat papan memiliki rongga-rongga udara kecil yang membuat papan menjadi lebih rapuh/mudah patah sehingga memiliki nilai kuat lentur yang tidak optimum lagi. Pada persentase serat $0,9 \%$ nilai kuat lentur papan beton $90 \mathrm{~kg} / \mathrm{cm}^{2}$ memenuhi standar mutu SNI yaitu $\geq 82,00 \mathrm{~kg} / \mathrm{cm}^{2}$. 


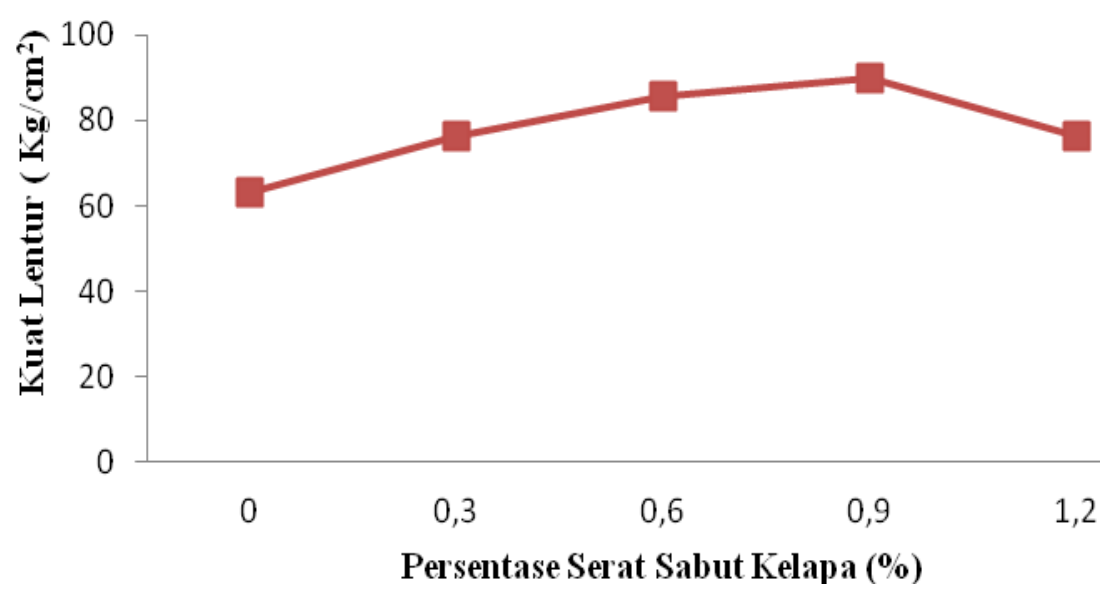

Gambar 4 Pengaruh Pengaruh Persentase Serat Sabut Kelapa dan Foam Agent Terhadap Kuat Lentur Papan Beton

\subsection{Kuat Tekan}

Hasil pengujian dan perhitungan kuat lentur menunjukkan bahwa penambahan serat sabut kelapa mempengaruhi kuat tekan papan beton, dimana penambahan serat sabut kelapa menyebabkan kuat tekan menurun. Berdasarkan Gambar 5 persentase $0,9 \%$ didapatkan nilai optimum kuat tekan dengan besar nilai $74,13 \mathrm{~kg} / \mathrm{cm}^{2}$. Adanya nilai optimum ini disebabkan oleh serat sabut kelapa memiliki kemampuan memperkuat ikatan matrik menjadi sempurna karna adanya selulosa serat, namun selulosa serat hanya bekerja baik pada kadar tertentu.

Penyebab lainya adalah ukuran diameter serat yang tidak seragam sehingga terdapat rongga udara pada papan yang mengakibatkan papan tidak padat dan bersifat rapuh Saat serat sabut kelapa ditambahkan secara berlebihan maka selulosa serat tidak akan bekerja dengan baik sehingga papan komposit beton ringan yang dihasilkan mengalami penurunan nilai kuat tekan. Selain itu papan beton sudah memenuhi nilai kuat tekan standar SNI 03-2105-2006.

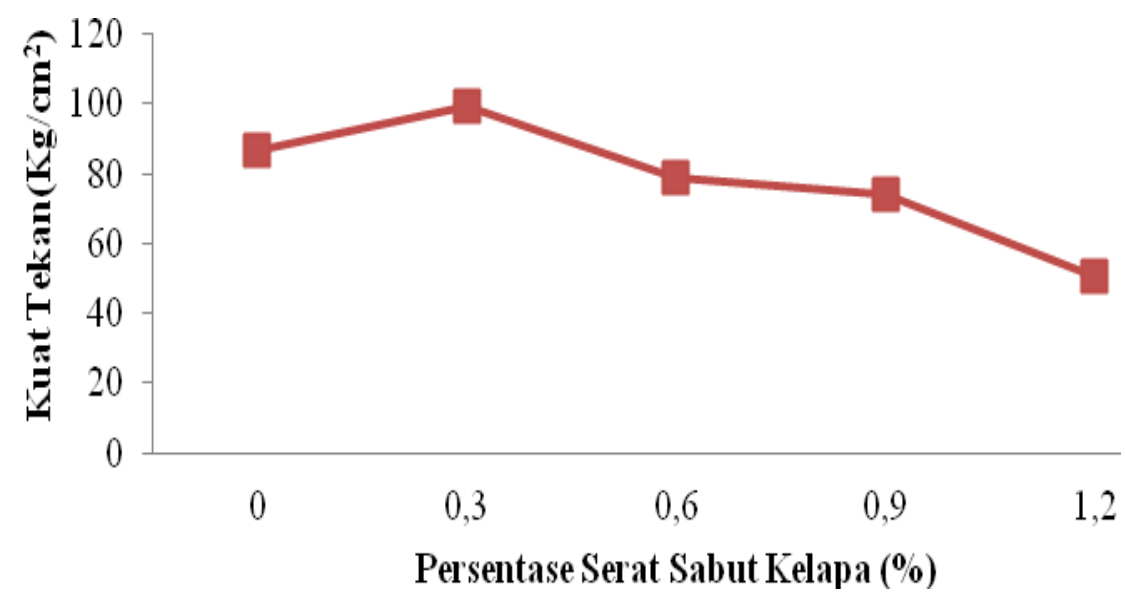

Gambar 5 Pengaruh Persentase Serat Sabut Kelapa dan Foam Agent Terhadap Kuat Lentur Papan Beton

\section{KESIMPULAN}

Penambahan foam agent $0,06 \%$ terhadap volume cetakan membentuk pori-pori pada papan sehingga papan lebih ringan dibandingkan papan beton tanpa foam agent. Papan beton dengan varisi serat sabut kelapa $0,9 \%$ menghasilkan nilai densitas, daya serap air, porositas, kuat tekaan dan kuat lentur yang optimum. 


\section{DAFTAR PUSTAKA}

Hull, Derek., 1981, An Introduction To Composite Materials, Cambridge Univ. Press, Cambridge.

Murtono, A., 2015, Pemanfaatan Foam Agent dan Material Lokal dalam Pembuatan Bata Ringan, Prosiding Seminar Nasional V Teknik Sipil, Universitas Muhammadiyah Surakarta, ISSN:2459-9727, Surakarta.

Sutigno, P., S. Kliwon.1977, Sifat Papan Semen Lima Jenis Kayu, Laporan No 96, Lembaga Penelitian Hasil Hutan, Bogor.

Zulkifly, 2013, Pengaruh Penambahan Serat Sabut Kelapa Terhadap Kuat Tekan Beton Pada Beton Normal, Jurnal Stabilita, Vol. 1 No. 2 April 2013, Fakultas Teknik Universitas Haluoleo.

Putranto., 2017, Pengaruh Fly Ash Sebagai Bahan Tambah Beton Ringan Foam Terhadap Berat Jenis, Kuat Tekan Dan Daya Serap Air Untuk Material Dinding Struktur, Jurnal Ilmiah Pendidikan Teknik Kejuruan (JIPTEK), Vol. X, No. 1, Universitas Sebelas Maret, Surakarta.

Umar, K., 2014, Pengaruh Penambahan Kadar Serabut Kelapa Pada Silinder Beton f'c 27,5 Mpa, Jurnal INTEKNA, No.1, Jurusan Teknik Sipil Politeknik Negeri Banjarmasin.

Wuryati, Samekto., 2001, Teknologi Beton, Kanisius, Yogjakarta. 